\title{
Formation mechanism of texture in $\alpha$-alumina coatings produced by aerosol deposition
}

\author{
Makoto HASEGAWA ${ }^{1, \dagger}$, Masahiro KOMURO ${ }^{2, \dagger \dagger}$, Kyonosuke KIMURA ${ }^{2, \dagger \dagger}$, Soma HASHIMOTO ${ }^{3, \dagger \dagger \dagger}$, \\ Makoto TANAKA ${ }^{4}$, Satoshi KITAOKA ${ }^{4}$ and Yutaka KAGAWA ${ }^{5}$ \\ ${ }^{1}$ Division of Systems Research, Faculty of Engineering, Yokohama National University, Yokohama 240-8501, Japan \\ ${ }^{2}$ Department of Systems Integration, Graduate School of Engineering, Yokohama National University, Yokohama 240-8501, Japan \\ ${ }^{3}$ Department of Mechanical Engineering, Materials Science, and Ocean Engineering, Graduate School of Engineering Science, \\ Yokohama National University, Yokohama 240_8501, Japan \\ ${ }^{4}$ Japan Fine Ceramics Center, Nagoya 456-8587, Japan \\ ${ }^{5}$ Katayanagi Advanced Research Lab., Tokyo University of Technology, Hachioji, Tokyo 192-0982, Japan
}

To investigate the texture formation mechanism in aerosol deposition (AD), coatings were deposited under various conditions using pure $\alpha-\mathrm{Al}_{2} \mathrm{O}_{3}$ powder particles. The deposition rate increased with increasing gas flow rate when the gas flow rate was in the range from 6 to $30 \mathrm{~L} / \mathrm{min}$. Furthermore, the deposition rate increased with increasing substrate heating temperature. No large difference in the microstructure of the $\alpha-\mathrm{Al}_{2} \mathrm{O}_{3}$ coating was observed. The formed $\alpha-\mathrm{Al}_{2} \mathrm{O}_{3}$ coatings was fully dense and crystalline. X-ray diffraction analysis of the coating surfaces revealed specific textures. A texture with (0001) planes tilted approximately $15^{\circ}$ from the coating plane was detected in the as-deposited specimen at a nozzle angle of $90^{\circ}$. Whether the nozzle angle was 90 and $60^{\circ}$, almost the same texture was formed indicating that the shear force does not contribute to texture formation. Texture formation was due to plastic deformation of the $\alpha-\mathrm{Al}_{2} \mathrm{O}_{3}$ powder during collisions with the substrate. This is thought to be due to activation of basal and pyramidal slip systems. When the substrate was heated during $\mathrm{AD}$, the texture changed to a (0001) fiber texture where the (0001) planes were parallel to the coating surface. The change in texture during substrate heating can be explained by a change in the critical resolved shear stress for the slip systems. The authors have previously reported that (0001) fiber texture has formed when the specimen was heat treated after the coating was deposited at room temperature. However, the mechanism of (0001) fiber texture formation by heat treatment is different form this research. During heat treatment, the texture is formed by the preferential growth of grains having (0001) plane at the surface of the coating.

(02021 The Ceramic Society of Japan. All rights reserved.

Key-words: Aerosol deposition, $\alpha-\mathrm{Al}_{2} \mathrm{O}_{3}$, Coating, Texture, Preferential orientation, X-ray diffraction (XRD), Schmid factor, Critical resolved shear stress (CRSS), Lattice rotation

[Received June 11, 2020; Accepted September 17, 2020]

\section{Introduction}

Trials to form coatings by powder impact were started in the $1970 \mathrm{~s}$. In electrostatic particle-impact deposition, the powder particles are accelerated to high speed by an electrostatic method. ${ }^{1), 2)}$ Before deposition, agglomerated particles are spontaneously separate and are refined due to charging of the powder particles. Attempts to form

Corresponding author: M. Hasegawa; E-mail: hasegawamakoto-zy@ynu.ac.jp

$\dagger \quad$ Present address: Nissan Co., Ltd.

tit Present address: JGC Plant Innovation Co., Ltd.

tit广 Present address: Graduate Student, Yokohama National University

titiो Preface for this article: Dol http://doi.org/10.2109/jcersj2. 129.P1-1 diamond-like coating have been made using this method. ${ }^{3)}$ In contrast, aerosol deposition (AD, also known as aerosol gas deposition, aerosol gas printing, or kinetic spray), developed by Hayashi et al. in the 1980s, produces coatings as a result of particle collisions in a gas flow. ${ }^{4)}$ The AD method gained recognition through research on deposition by Akedo. ${ }^{5), 6)}$ Many powders such as $\mathrm{ZrO}_{2},{ }^{7)-10)} \quad \alpha-\mathrm{Al}_{2} \mathrm{O}_{3},{ }^{5), 6), 11)-18)} \quad$ Mullite, ${ }^{19)} \quad \beta$-SiAlON, ${ }^{20)}$ $\mathrm{Pb}\left(\mathrm{Zr}_{52}, \mathrm{Ti}_{48}\right) \mathrm{O}_{3},{ }^{6,21)} \mathrm{Ni}-\mathrm{Zn}-\mathrm{Fe}_{3} \mathrm{O}_{4},{ }^{6)} \mathrm{Li}_{4} \mathrm{Ti}_{5} \mathrm{O}_{12},{ }^{22}$ AlN, $\left.{ }^{6}\right)$ $\mathrm{TiN},{ }^{23)} \mathrm{MgB}_{2},{ }^{6)} \mathrm{Ni}^{24)}$ and $\mathrm{Cu}^{25)}$ have been used to produce coatings by AD.

The AD method can form dense, crystalline ceramic coatings, ${ }^{5), 6)}$ and therefore this approach is promising for high-temperature applications. For example, in order to use a $\mathrm{SiC}$ fiber-reinforced $\mathrm{SiC}$ matrix composite at high temperature, dense environmental barrier coatings (EBCs) are required. Conventional EBCs produced by atmospheric 
plasma spraying are porous and in some cases amorphous. Such porous coatings can undergo sintering when used at high temperature, which causes shrinkage of the coating. In amorphous coatings, shrinkage occurs due to recrystallization from the amorphous state. Shrinkage causes a tensile load on the coating parallel to the interface and cracks perpendicular to the interface are often observed in coatings formed by the thermal spraying method. Damage to such coatings by these vertical cracks leads to a decrease in environmental barrier performance and delamination of the coating. ${ }^{26)-29)}$ On the other hand, since the AD method can form dense, crystalline coatings at room temperature, it can suppress damage to the substrate from oxidation and subsequent volatilization due to water vapor. Therefore, coatings produced by the AD method have been considered for application to EBCs as gas shielding coatings ${ }^{19), 20)}$ and to advanced EBCs for reflecting radiation heat. ${ }^{30)}$

It is thought that coatings prepared by the $\mathrm{AD}$ method are formed by fracture and plastic deformation of particles at the time of collision with the substrate. This coating formation principle is called room-temperature impact consolidation. ${ }^{5), 6)}$ It has been proposed that the deposition of particles occurs due to plasma generation by the collision of electrons with the deposition gas.9),10)

In polycrystalline metals, alloys, intermetallic compounds, and ceramics, texture is formed by plastic deformation due to activation of slip or twin systems. ${ }^{31)-39)}$ Investigations of coatings prepared by $\mathrm{AD}$ using nickel or $\alpha-\mathrm{Al}_{2} \mathrm{O}_{3}$ powder have identified the formation of texture. ${ }^{14), 15), 24)}$ In the case of a nickel coating, a $\{011\}$ fiber texture, in which $\{011\}$ planes are parallel to the deposition plane, was formed. ${ }^{24)}$ For $\alpha-\mathrm{Al}_{2} \mathrm{O}_{3}$ coatings, a fiber texture was formed where the (0001) planes were inclined approximately $15^{\circ}$ from the deposition plane. ${ }^{14)}$ Nickel has an fcc structure, for which the stable orientation for uniaxial compressive deformation of the polycrystalline material is $\{011\} .{ }^{31)}$ However, for $\alpha-\mathrm{Al}_{2} \mathrm{O}_{3}$, it was not clear why the inclined fiber texture was formed.

In the present study, coatings are formed under various deposition conditions by the AD method using $\alpha-\mathrm{Al}_{2} \mathrm{O}_{3}$ powder, whose slip and twin systems are already known. Texture formation was studied considering the active slip systems and the critical resolved shear stress (CRSS) for each slip system. The effect of substrate heating on texture formation was also considered.

\section{Experimental}

\subsection{Formation of $\alpha-\mathrm{Al}_{2} \mathrm{O}_{3}$ coating}

Commercially available pure $\alpha-\mathrm{Al}_{2} \mathrm{O}_{3}$ powder (TMDAR, Taimei Chemicals Co. Ltd., Nagano, Japan) was used to form the coatings. Figure 1 shows a scanning electron microscopy (SEM) image of the $\alpha-\mathrm{Al}_{2} \mathrm{O}_{3}$ powder. The average particle size was $0.14 \mu \mathrm{m}$. The powder particles have roughly equiaxed shapes. The purity of the powder was 99.9 mass \% (impurities: Si 3 ppm, Fe 3 ppm, Na 3 ppm, K 1 ppm, Ca 2 ppm, Mg 1 ppm). Before deposition, the powder was dried in air at $523 \mathrm{~K}$ for $12 \mathrm{~h}$. The

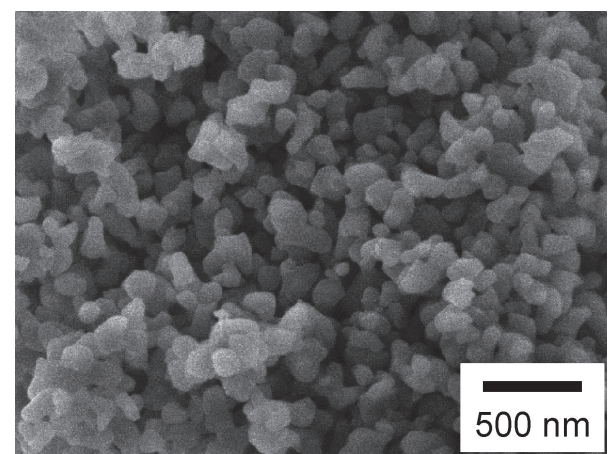

Fig. 1. Scanning electron micrograph of $\alpha-\mathrm{Al}_{2} \mathrm{O}_{3}$ powders used for AD coating.

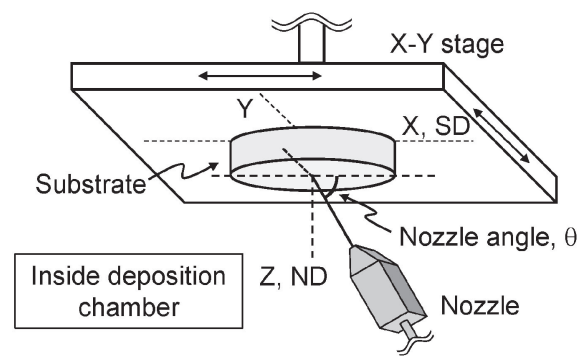

Fig. 2. Schematic illustration showing the relationship of the angle between the substrate and the direction of flow from the nozzle (nozzle angle).

coatings were deposited at room temperature by AD (Type GD-AE04/SS2, Fuchita Nanotechnology, Ltd., Tsukuba, Japan). A glove box was attached to the AD device and an aerosol chamber was installed inside the glove box. The dried powder was cooled in the glove box filled with dry $\mathrm{N}_{2}$ gas and then loaded into the aerosol chamber. This allowed the deposition of coatings with fewer agglomerated particles and suppressed large variations in the coating thickness, deposition rate, and microstructure due to humidity. A Mo disc with a diameter of $15 \mathrm{~mm}$ and a thickness $3 \mathrm{~mm}$ was used as the substrate. Prior to deposition, the substrate surface was polished with diamond paste. The roughness of the polished surface was $\mathrm{Ra}=7 \mathrm{~nm}$. The substrate was then subjected to ultrasonic cleaning using ethanol. He and $\mathrm{N}_{2}$ were used as carrier gases for $\mathrm{AD}$, allowing the deposition of coatings at a wide range of particle velocities. The dimensions (width $\times$ thickness) of the nozzle port were $5 \mathrm{~mm} \times 0.5 \mathrm{~mm}$. During the AD process, the gas flow rate, nozzle-substrate distance, scanning speed, and number of scans were $8-30 \mathrm{~L} / \mathrm{min}, 7 \mathrm{~mm}, 150 \mathrm{~mm} / \mathrm{min}$, and 30 times, respectively. The relationship of the angle between the substrate and the direction of flow from the nozzle (nozzle angle) is shown schematically in Fig. 2. The nozzle angle is decided at $\mathrm{X}-\mathrm{Z}$ plane. Deposition was done at the nozzle angle of 90 and $60^{\circ}$. Deposition was also performed when the substrate was heated. The substrate temperature was varied from $300 \mathrm{~K}$ (room temperature) to $573 \mathrm{~K}$. If the coating thickness was less than $1 \mu \mathrm{m}$, the specimen was recoated until it became $1 \mu \mathrm{m}$ thick. 


\subsection{Microstructure and texture characterization}

After deposition, the surface and cross-section of the coating were observed by SEM (JSM-7001F, JEOL Ltd., Tokyo, Japan; SU8010, Hitachi High-Technologies Corp., Tokyo, Japan). The cross-section before observation was prepared using ion milling (IM4000, Hitachi HighTechnologies Corp., Tokyo, Japan). The thickness and surface roughness of the deposited coating were measured by a surface roughness meter (ET200, Kosaka Laboratory Ltd., Tokyo, Japan). The texture of the coating was determined by X-ray diffraction (XRD).

The texture was characterized using the Schulz reflection method, with $\mathrm{Cu}-\mathrm{K} \alpha$ radiation filtered by a monochromator (Ultima IV, Rigaku Co., Tokyo, Japan), with an $\mathrm{X}$-ray tube voltage and tube current of $40 \mathrm{kV}$ and $40 \mathrm{~mA}$, respectively. To prevent overlap between the $\alpha-\mathrm{Al}_{2} \mathrm{O}_{3}$ diffraction peaks and those from the substrate, a Mo substrate was used for the measurements. The intensities of the $10 \overline{1} 2,10 \overline{1} 4$, and $11 \overline{2} 3$ peaks of rhombohedral $\alpha-\mathrm{Al}_{2} \mathrm{O}_{3}$ were measured. From the pole figures obtained, the orientation distribution function (ODF) was calculated by the arbitrarily defined cell method ${ }^{40)}$ (LaboTex Ver. 3.0.24, LaboSoft s. c., Krakow, Poland). The main component and sharpness of the texture, which correspond to the position and value of the maximum pole density, were determined from the normalized pole figure and the inverse pole figure derived from the ODF. The normalized pole density, $\mathrm{P}(\alpha, \beta)$, can be expressed as

$$
\mathrm{P}(\alpha, \beta)=\frac{I(\alpha, \beta)}{\frac{1}{2 \pi} \int_{\alpha=0}^{\alpha=\pi / 2} \int_{\beta=0}^{\beta=2 \pi} I(\alpha, \beta) \sin \alpha d \alpha d \beta},
$$

where $\mathrm{I}(\alpha, \beta), \alpha$ and $\beta$ are the non-normalized intensity, radial angle, and azimuthal angle, respectively. ${ }^{41)}$ For a random specimen, $\mathrm{P}(\alpha, \beta)$ will be 1.0 (mean pole density). The volume fractions for the regions aligned within $15^{\circ}$ of the main component were calculated.

\section{Results}

\subsection{Deposition rate and microstructure}

Figure 3 shows the change in $\alpha-\mathrm{Al}_{2} \mathrm{O}_{3}$ deposition rate as a function of the gas flow rate and the substrate temperature at a nozzle angle of $90^{\circ}$. The deposition rate was evaluated in a region of $5 \mathrm{~mm} \times 5 \mathrm{~mm}$ (nozzle width $\times$ scanning distance equal to the nozzle width). Figure 3(a) shows the effect of the gas flow rate on the deposition rate deposited at $300 \mathrm{~K}$ (room temperature). For both $\mathrm{N}_{2}$ and He gas, the deposition rate increased with increasing gas flow rate up to $30 \mathrm{~L} / \mathrm{min}$. The increase in the deposition rate with increasing gas flow rate tends to decrease as the gas flow rate increases. However, no peak and subsequent decrease in the deposition rate were observed, due to the limitations of our AD equipment, which cannot operate with a gas flow rate higher than $30 \mathrm{~L} / \mathrm{min}$. It has been reported that the deposition rate usually increases up to a maximum value and then decreases with increasing gas flow rate. ${ }^{16), 19), 23), 24)}$ Figure 3(b) shows the effect of the substrate temperature on the deposition rate. Here, $\mathrm{N}_{2}$ gas
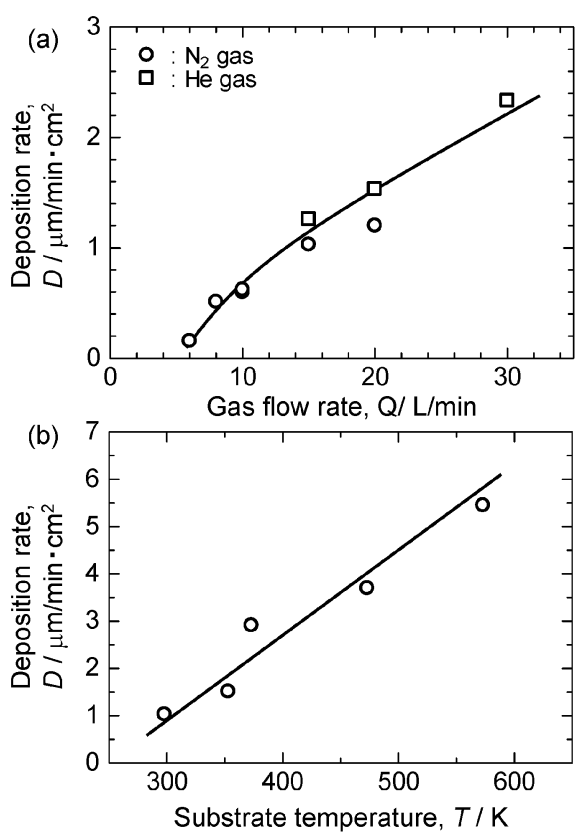

Fig. 3. Variation of deposition rate as a function of (a) gas flow rate and (b) substrate temperature.

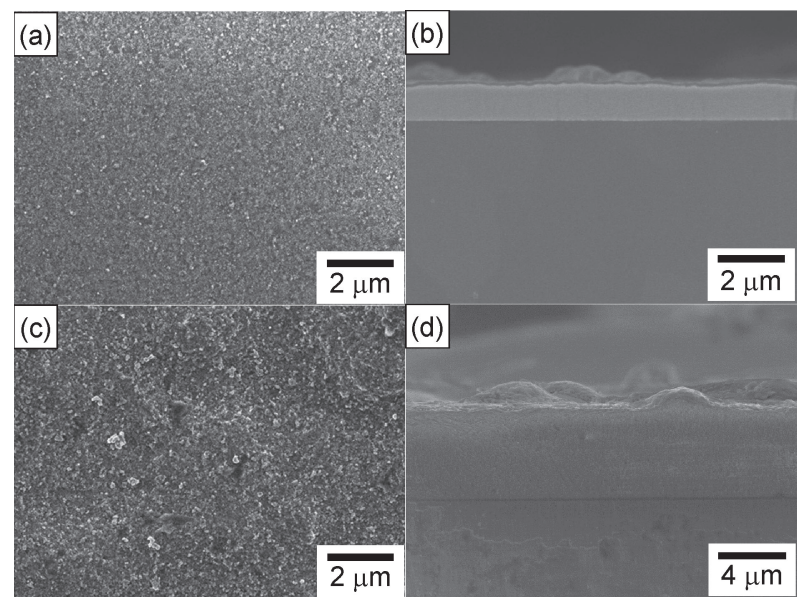

Fig. 4. Scanning electron micrographs showing $(\mathrm{a}, \mathrm{c})$ surface and $(b, d)$ cross-section of an $\alpha-\mathrm{Al}_{2} \mathrm{O}_{3}$ coating deposited on a Mo substrate: (a, b) deposited at $300 \mathrm{~K}$ (room temperature), and (c, d) deposited at $573 \mathrm{~K}$.

was used for the deposition where the gas flow rate was fixed at $15 \mathrm{~L} / \mathrm{min}$. The deposition rate increases with increasing substrate temperature. However, when the substrate is heated to $573 \mathrm{~K}$ during deposition, partial delamination or unbonded regions of the coating were detected at the edge of the substrate. However, delamination was not detected at the central part of the coated substrate. Figure 4 shows surface and cross-sectional SEM micrographs of an $\alpha-\mathrm{Al}_{2} \mathrm{O}_{3}$ coating deposited at $300 \mathrm{~K}$ (room temperature) and $573 \mathrm{~K}$. This coating was deposited at a gas flow rate of $15 \mathrm{~L} / \mathrm{min}$. Regardless of the substrate temperature, no cracks or chips could be observed on the surface of the coating at the central part of the specimen [Figs. 4(a) and 4(c)]. Figures 4(b) and 4(d) show a 
cross-section of the coating at the central part of the specimen, in which it can be seen that a dense coating is produced. Furthermore, no delamination is observed between the substrate and the coating. Mo, which is the substrate used in this research, has lower hardness than mullite. Therefore, $\mathrm{Al}_{2} \mathrm{O}_{3} / \mathrm{Mo}$ interface produced by $\mathrm{AD}$ was considered to be more undulated than the $\mathrm{Al}_{2} \mathrm{O}_{3} /$ mullite interface shown in Ref. 14. However, SEM observations at the high magnification did not show any significant difference at the interface.

\subsection{Texture}

Figure 5 shows the texture determined by XRD for a coating deposited at a $\mathrm{N}_{2}$ gas flow rate of $15 \mathrm{~L} / \mathrm{min}$ at a nozzle angle of $90^{\circ}$. Figures 5(a) and 5(b) show (0001) and $\{10 \overline{1} 0\}$ pole figures, respectively. The pole densities are projected onto the coating plane. Figures 5(c) and 5(d) show inverse pole figures from the normal direction (ND) and side direction (SD) relative to the coating plane, respectively. The mean pole density is used as a unit. The pole figure shows the orientation distribution in the specimen coordinate system. The X (SD), Y, and Z (ND) axes in the specimen indicated in Fig. 2 are defined in the pole figure as shown in Fig. 5(e). These pole figures indicate that the coating has a fiber texture. In the (0001) pole figure, the highest pole density has an orientation approx- imately $15^{\circ}$ from the center. In the $\{10 \overline{1} 0\}$ pole figure, the pole density is distributed $15^{\circ}$ inward of the great circle. This result indicates that the angular relationship between the $(0001)$ and $\{10 \overline{1} 0\}$ planes is $90^{\circ}$. This relationship is the same as that between crystal planes in the rhombohedral lattice. Thus, it can be concluded that there are no serious errors in the analyzed textures. Figure 5(c) shows an inverse pole figure for the ND. The maximum pole density is oriented approximately $15^{\circ}$ from the (0001) plane. The maximum pole density is 5.5 times higher than the random level. In this case, the volume fraction for the regions aligned within $15^{\circ}$ of the main component was $21.9 \%$. In the inverse pole figure for the $\mathrm{SD}$, the region of high pole density spreads about $15^{\circ}$ inward from the $(2 \overline{1} 10)$ to the $(1 \overline{1} 0)$ planes. In this case, the maximum pole density is 1.5 . This is a characteristic of a fiber texture. Therefore, an analysis based on ODF calculations is required to determine the preferential orientation. Evaluating the preferential orientation only from cross-section using selected area electron diffraction pattern from transmission electron microscope may sometime give misleading results, as it could be evaluated as random in the coating even if there is a preferential orientation for the ND. Figure 6 shows the change in texture with increasing gas flow rate at a nozzle angle of $90^{\circ}$. Figures 6(a)-6(c) show inverse pole figures for different types of gas and gas

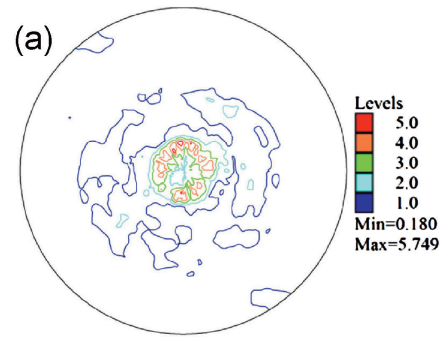

(0001)

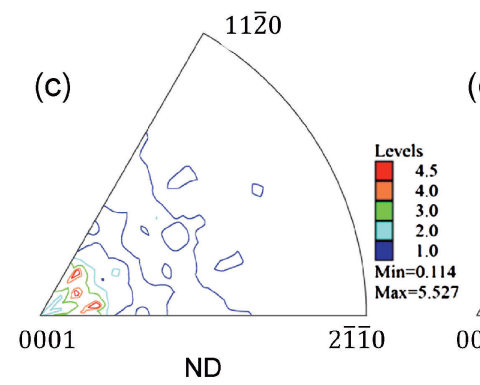

ND

(e)

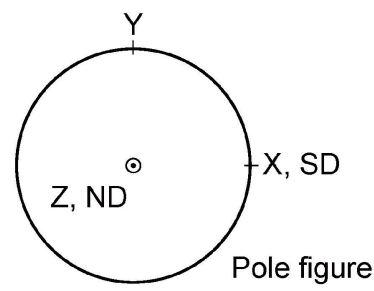

(b)

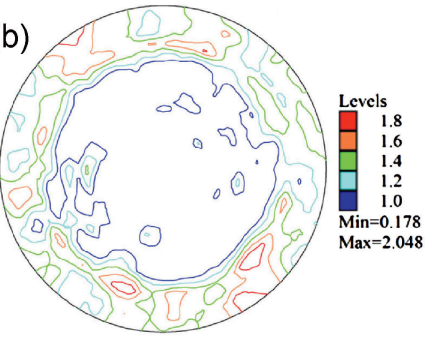

$\{10 \overline{1} 0\}$

(d)

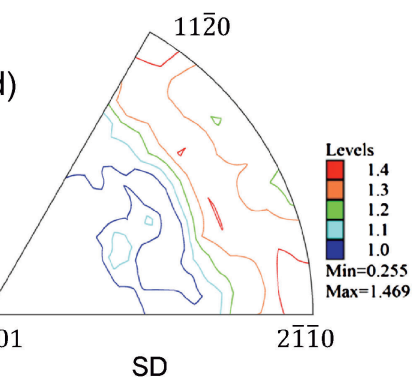

Fig. 5. Orientation distribution of an $\alpha-\mathrm{Al}_{2} \mathrm{O}_{3}$ coating deposited at a nozzle angle of $90^{\circ}$. (a) (0001) pole figure, (b) $\{10 \overline{1} 0\}$ pole figure, (c) inverse pole figure for the ND, and (d) inverse pole figure for the SD. (e) Definition of the $\mathrm{X}(\mathrm{SD}), \mathrm{Y}$, and $\mathrm{Z}(\mathrm{ND})$ axes of the deposited specimen in the pole figure. 

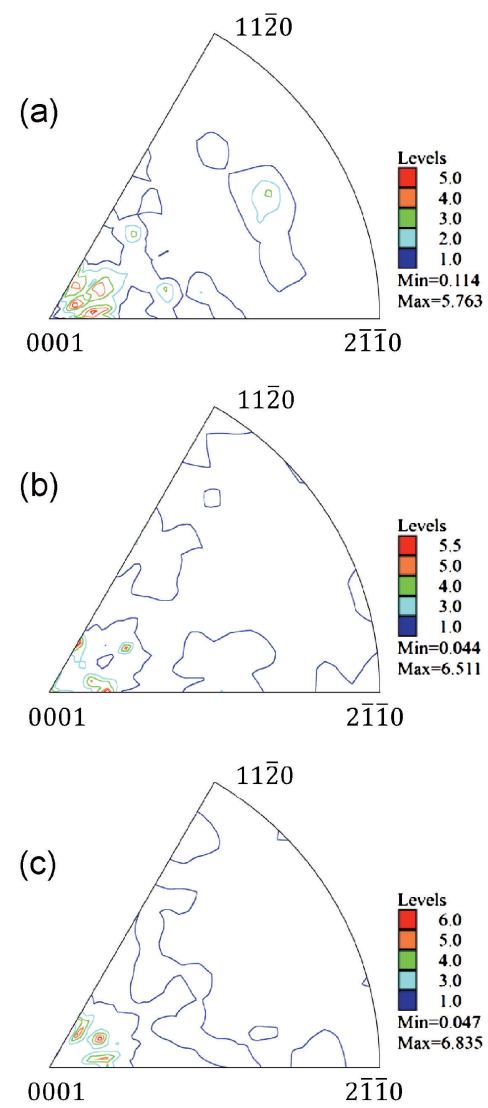

Fig. 6. Inverse pole figures for the ND for different gas flow rates and different gasses. Deposited at (a) $8 \mathrm{~L} / \mathrm{min}\left(\mathrm{N}_{2}\right)$, (b) $10 \mathrm{~L} / \mathrm{min}\left(\mathrm{N}_{2}\right)$, and (c) $15 \mathrm{~L} / \mathrm{min}(\mathrm{He})$.

flow rates. The main texture component is independent of the type of gas and the gas flow rate, and is inclined about $15^{\circ}$ from the (0001) plane. However, the maximum pole density increases with increasing gas flow rate. The change in volume fraction of the main component is shown in Fig. 7. The volume fraction of the main component increases with increasing gas flow rate. However, when the gas flow rate reaches $20 \mathrm{~L} / \mathrm{min}$, no further increase in the volume fraction of the main component is observed. This indicates that the texture does not develop further above a certain gas flow rate. Figure 8 shows the texture for a nozzle angle of $60^{\circ}$ and a $\mathrm{N}_{2}$ gas flow rate of $15 \mathrm{~L} / \mathrm{min}$. Figures $8(\mathrm{a})$ and $8(\mathrm{~b})$ show the $(0001)$ and $\{10 \overline{1} 0\}$ pole figures, respectively. The pole densities are projected onto the coating plane. Figures $8(\mathrm{c})$ and $8(\mathrm{~d})$ shows inverse pole figures for the ND and SD, respectively. The mean pole density is used as a unit. In the (0001) pole figure, the highest pole density has an orientation approximately $15^{\circ}$ from the center. In the $\{10 \overline{10}\}$ pole figure, the pole density is distributed about $15^{\circ}$ inward of the great circle. Figure $8(\mathrm{c})$ shows an inverse pole figure from the ND. The maximum pole density is oriented approximately $15^{\circ}$ from the (0001) plane. The maximum pole density is 2.7 times higher than the random level. In this case, the volume fraction for the regions aligned within $15^{\circ}$ of the main component was $29.4 \%$. In the inverse pole figure for the $\mathrm{SD}$, the region of high pole density spreads about $15^{\circ}$

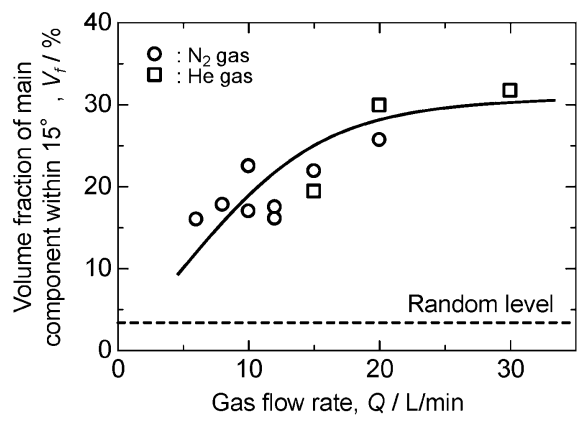

Fig. 7. Relationship between the volume fraction of the main component and the gas flow rate.

inward from $(2 \overline{1} \overline{1} 0)$ to the $(11 \overline{2} 0)$ plane. In this case, the maximum pole density is 1.3 . These show the same characteristics as the coating deposited at a nozzle angle of $90^{\circ}$. This indicates that the force of the shear component during particle collision does not contribute to the formation of the texture. That is, shear deformation of the particles does not occur during $\mathrm{AD}$.

Figures 9(a) and 9(b) show inverse pole figures for the ND when the substrate was heated at 373 and $573 \mathrm{~K}$ during deposition at a nozzle angle of $90^{\circ}$. The gas was $\mathrm{N}_{2}$ and the gas flow rate was $15 \mathrm{~L} / \mathrm{min}$. For all conditions, the maximum pole density is oriented at the (0001) plane. Figure 10 shows the distribution of the volume fraction of the main component as a function of substrate temperature. The circle and triangle symbols indicate the main (0001) plane component and that approximately $15^{\circ}$ from the (0001) plane, respectively. For the coating deposited at $300 \mathrm{~K}$, the main component is approximately $15^{\circ}$ from the (0001) plane. However, when the substrate was heated to over $353 \mathrm{~K}$, the main component is associated with the (0001) plane. In addition, independent of substrate temperature, the main component is roughly ranging from 17 to $25 \%$.

\section{Discussion}

\subsection{Texture formation in $\alpha-\mathrm{Al}_{2} \mathrm{O}_{3}$ coating by AD method}

Coating by $\mathrm{AD}$ is considered to proceed either by the generation of plasma ${ }^{9), 10)}$ or room-temperature impact consolidation. ${ }^{5), 6)}$ In the former process, the surface of the particles is activated by the generation of plasma, and the particles combine randomly with each other to form a coating. It is considered that in this process a texture having a preferential orientation will not form. Room-temperature impact consolidation has been reported to occur by fracture and plastic deformation of particles. ${ }^{5), 6)}$ For the coating using mixed particles of $\alpha-\mathrm{Al}_{2} \mathrm{O}_{3}$ and PZT, Akedo observed from the cross-section of the coating that the spherical particles before deposition became plate-like particles during deposition. ${ }^{5), 6)}$ In case of microcompression tests conducted on $\alpha-\mathrm{Al}_{2} \mathrm{O}_{3}$ particles, when the particle diameter was $3 \mu \mathrm{m}$, brittle fracture and fragmentation were reported. However, when the particle diameter was $0.3 \mu \mathrm{m}$, significant plastic deformation and 


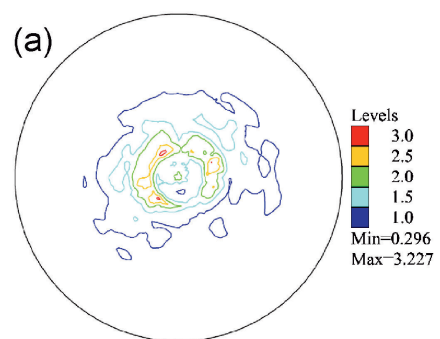

(0001)

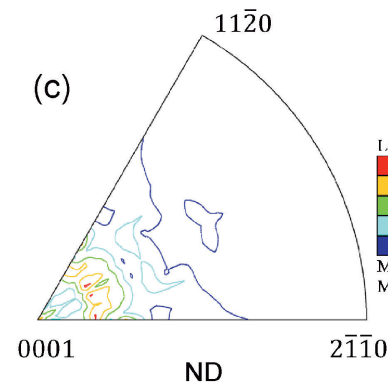

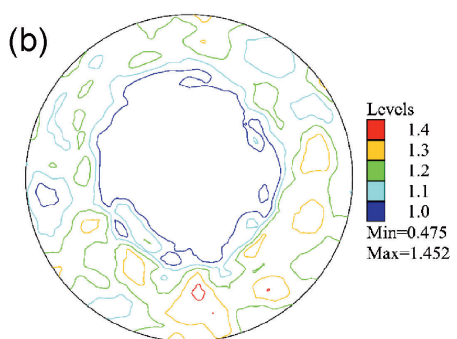

$\{10 \overline{1} 0\}$

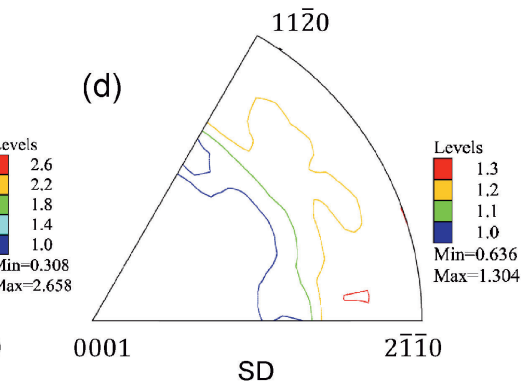

Fig. 8. Orientation distribution of an $\alpha-\mathrm{Al}_{2} \mathrm{O}_{3}$ coating deposited at a nozzle angle of $60^{\circ}$. (a) (0001) pole figure, (b) $\{10 \overline{1} 0\}$ pole figure, (c) inverse pole figure for the $\mathrm{ND}$, and (d) inverse pole figure for the SD.
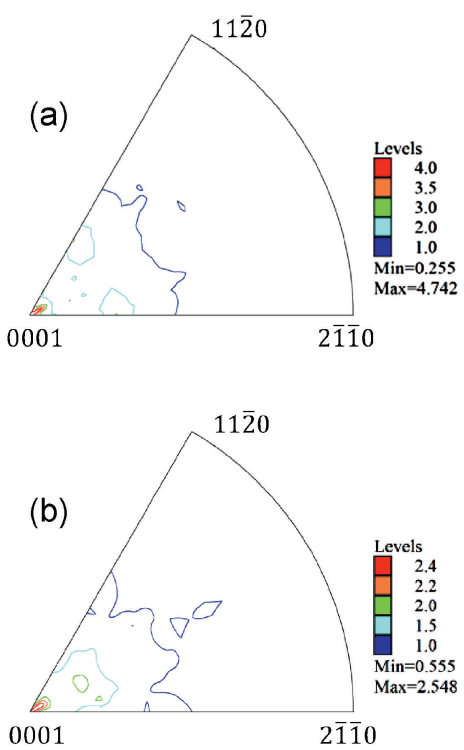

Fig. 9. Inverse pole figures for the ND for different substrate temperatures. Deposited at (a) $373 \mathrm{~K}$ and (b) $573 \mathrm{~K}$.

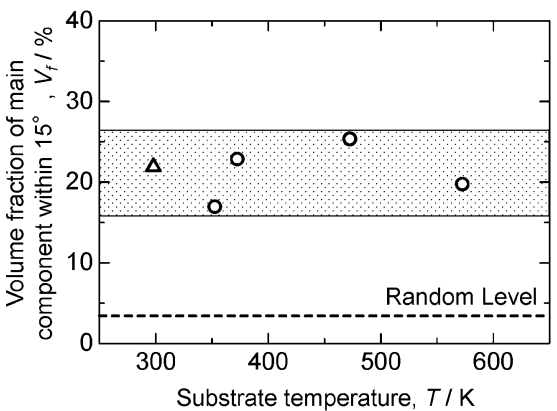

Fig. 10. Relationship between the volume fraction of the main component and the substrate temperature. cracking without fragmentation were observed. ${ }^{42)}$ In molecular dynamics simulations, it was found that in the compressive deformation of an $\mathrm{Al}_{2} \mathrm{O}_{3}$ single crystal having a diameter of $10 \mathrm{~nm}$, undergoes plastic deformation due to the activation of two slip systems. ${ }^{42)}$ From these observations, it was considered that plastic deformation occurred in the particles. ${ }^{5), 6), 42)}$ Furthermore, in an investigation of the texture of a coating obtained by deposition of Ni powder by AD at a nozzle angle of $90^{\circ}$, a $\{011\}$ fiber texture was produced, which is almost the same as that obtained by uniaxial deformation of Ni bulk material. ${ }^{24)}$ In addition, a fiber texture with (0001) planes inclined about $15^{\circ}$ from the coating plane was formed in $\alpha-\mathrm{Al}_{2} \mathrm{O}_{3} \cdot{ }^{14)}$ However, it has not been clarified why this texture is formed.

For bulk $\alpha-\mathrm{Al}_{2} \mathrm{O}_{3}$, deformation involving multiple slip and occasional twinning has been detected over a wide range of compressive strain rates from $10^{-4}$ to $10^{6} \mathrm{~s}^{-1}$. Mechanical tests were performed by indentation, servocontrolled hydraulic testing, split Hopkinson pressure bar testing, and a flyer plate experiment, for strain rates of $3.5 \times 10^{-3}, 10^{-4}-100,500-2500$, and $10^{5}-10^{6} \mathrm{~s}^{-1}$, respectively. ${ }^{43)}$ Basal slip, non-basal slip (prism slip and pyramidal slip), basal twinning, and rhombohedral twinning have been reported to become activated for sapphire single crystals under an indentation test. ${ }^{44), 45)}$ Basal slip, basal twinning, and slip along the (0001) plane having a $\langle 10 \overline{10}\rangle$ Burgers vector have been observed in sapphire under shock loading at room temperature. ${ }^{46)}$ Furthermore, transgranular fracture, intergranular fracture, basal slip, prism slip, and twinning have been observed for polycrystalline $\mathrm{Al}_{2} \mathrm{O}_{3}$ during impact compression. ${ }^{47)}$ As we have discussed in Ref. 14, fractures are not dominant in the formation of texture, based on the energy of the cleavage plane and the fracture plane for $\alpha-\mathrm{Al}_{2} \mathrm{O}_{3}$ deposition by 


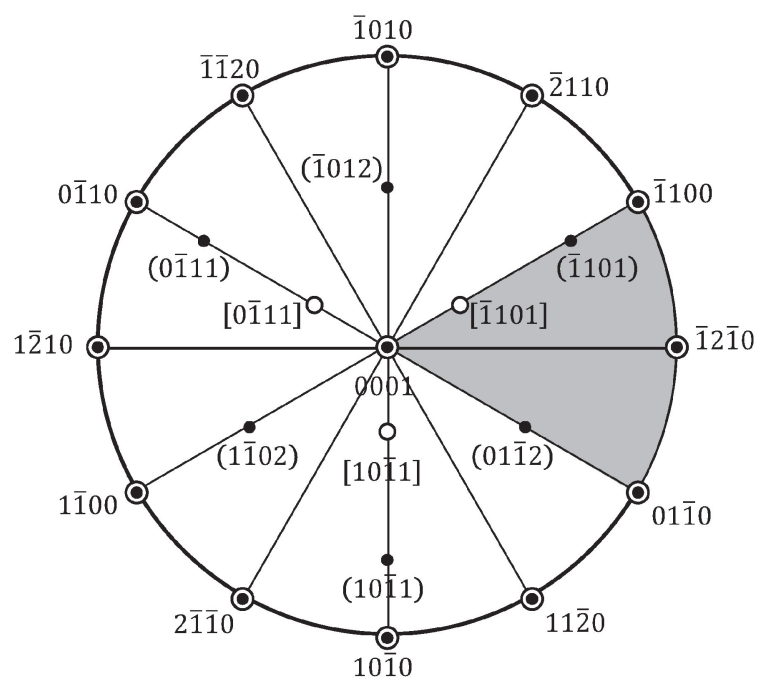

Fig. 11. Standard (0001) projection of $\alpha-\mathrm{Al}_{2} \mathrm{O}_{3}$ showing slip planes (filled circles) and slip directions (open circles). ${ }^{52)}$ The gray region is the standard unit stereographic triangle for the $\alpha$ $\mathrm{Al}_{2} \mathrm{O}_{3}$ system.

AD. ${ }^{14)}$ Therefore, we focus on the Schmid factor and the CRSS for each slip system. Texture formation taking the crystal lattice rotation into consideration is then examined.

Several kinds of slip systems, such as $(0001)\langle 11 \overline{2} 0\rangle$ (basal slip), $\{11 \overline{2} 0\}\langle 1 \overline{1} 00\rangle$ (prism slip), and $\{10 \overline{1} 1\}\langle\overline{1} 101\rangle$ (pyramidal slip), and twin systems such as $(0001)\langle 01 \overline{1} 0\rangle$ (basal twin) and $\{01 \overline{1} 2\}\langle\overline{1} 01 \overline{1}\rangle$ (rhombohedral twin), have been reported for $\alpha-\mathrm{Al}_{2} \mathrm{O}_{3}$. $\left.{ }^{48}\right)$ The dependence on temperature of the shear stress for an initial yield by slip and twinning, which relates to the CRSS in $\mathrm{Al}_{2} \mathrm{O}_{3}$, has been determined by Clayton. ${ }^{48), 49)}$ Shear stress in each slip and twin system decreases with increasing temperature. ${ }^{48)-50)}$ The shear stress at $300 \mathrm{~K}$ for basal slip, prism slip, pyramidal slip, basal twins, and rhombohedral twins is 4.2, 3.2, $6.2,4.3$, and $0.9 \mathrm{GPa}$, respectively. Rhombohedral twins have the lowest shear stress. However, such twins are activated only under tensile loading. ${ }^{48)}$ Furthermore, twinning is not observed for $\alpha-\mathrm{Al}_{2} \mathrm{O}_{3}$ particles. ${ }^{51)}$ Thus, it is acceptable to presume activation of slip systems only under compressive loading. Figure 11 shows the standard (0001) projection of $\alpha-\mathrm{Al}_{2} \mathrm{O}_{3}$ showing the slip planes (filled circles) and slip directions (open circles). ${ }^{52)}$ Due to the positions of the $\mathrm{Al}$ atoms at the available cation sites, the $c$-axis has only 3 -fold rotational symmetry. Thus, the gray region is the standard unit stereographic triangle, in which there are seven main slip systems:(0001)[12 10$]$, (12 $\overline{1} 0)[\overline{1} 010],(\overline{1} 2 \overline{1} 0)[10 \overline{1} 0],(\overline{2} 110)[01 \overline{1} 0],(11 \overline{2} 0)[\overline{1} 100]$, (1101)[10 $\overline{1} 1]$, and (10 $\overline{1} 1)[\overline{1} 101]$.

Generally, in a single slip system, the slip plane is parallel to the compression plane when the material is compressed. ${ }^{53)}$ However, when multiple equivalent slip systems are active, as in the case of an fcc lattice, the active slip system is determined by the Schmid factor, which depends on the crystal orientation relative to the compression axis. Therefore, when the orientation changes due to lattice rotation, the slip system having the highest Schmid factor is activated. The slip system for a material with an fcc lattice is only $\{111\}\langle 110\rangle$, and the CRSS for the active slip system is the same. Therefore, there is no need to consider the value of the CRSS. Hence, for uniaxial compressive deformation of an fcc material, lattice rotation eventually occurs to $\{011\}$, which is the stable deformation orientation during compression, due to double slip. ${ }^{31), 33)} \mathrm{A}$ $\{011\}$ fiber texture similar to that obtained for uniaxial deformation of Ni bulk material was formed during deposition of Ni powder by AD. ${ }^{24)}$ Therefore, texture formation can be explained as being the consequence of the lattice rotation caused by activation of each slip system in $\alpha$ $\mathrm{Al}_{2} \mathrm{O}_{3}$. However, in $\alpha-\mathrm{Al}_{2} \mathrm{O}_{3}$, basal, prism, and pyramidal slip systems, which are not equivalent slip systems, are active, and thus the CRSS is different in each slip system. Therefore, it is not possible to determine the active slip system for the crystal orientation facing the compression axis only by the Schmid factor. Thus, the Schmid factor considering the CRSS in each slip system was investigated.

When any position in the standard unit stereographic triangle is considered as being the direction of the compression axis, the Schmid factors for basal, prism, and pyramidal slip systems for each compression axis are represented by $m_{\text {bas }}, m_{\text {pri }}$, and $m_{\text {pyr }}$, respectively. As we have described above, the order of the CRSS from highest to lowest for each slip system at $300 \mathrm{~K}$ is pyramidal, basal, and prism. For this reason, even for the same value of the Schmid factor, the slip system having a higher CRSS will be less active. The normalized Schmid factor for basal, prism, and pyramidal slip systems at $300 \mathrm{~K}$ are expressed as $m_{\mathrm{bas}}^{\mathrm{n} \mathrm{RT}}, m_{\mathrm{pri}}^{\mathrm{n} \mathrm{RT}}$, and $m_{\mathrm{pyr}}^{\mathrm{m} \mathrm{RT}}$, respectively, and are given by

$$
\begin{aligned}
& m_{\mathrm{bas}}^{\mathrm{n} \mathrm{RT}}=\frac{m_{\mathrm{bas}}}{\left(\frac{\tau_{\mathrm{bas}}^{\mathrm{RT}}}{\tau_{\mathrm{pri}}^{\mathrm{RT}}}\right)} \\
& m_{\mathrm{pri}}^{\mathrm{n} \mathrm{RT}}=\frac{m_{\mathrm{pri}}}{\left(\frac{\tau_{\mathrm{pri}}^{\mathrm{RT}}}{\tau_{\mathrm{pri}}^{\mathrm{RT}}}\right)} \\
& m_{\mathrm{pyr}}^{\mathrm{n} \mathrm{RT}}=\frac{m_{\mathrm{pyr}}}{\left(\frac{\tau_{\mathrm{pyr}}^{\mathrm{RT}}}{\tau_{\mathrm{pri}}^{\mathrm{RT}}}\right)}
\end{aligned}
$$

where $\tau_{\text {bas }}^{\mathrm{RT}}, \tau_{\text {pri }}^{\mathrm{RT}}$, and $\tau_{\text {pyr }}^{\mathrm{RT}}$ are the CRSS for the basal, prism and pyramidal slip system at $300 \mathrm{~K}$, respectively.

After determining the normalized Schmid factor for each slip system and each compression axis, the normalized Schmid factor with the highest value for each compression axis is plotted in Fig. 12. Figure 12(a) shows the normalized Schmid factor on the great circle from (0001) to $(\overline{1} 2 \overline{1} 0)$. The direction of lattice rotation for each slip system on the great circle is indicated by arrows. The highest values of the normalized Schmid factor for a pyramidal slip system range from 0 to $19^{\circ}$. In the basal and prims slip systems, the highest values range from 19 to $60^{\circ}$ and from 60 to $90^{\circ}$, respectively. Further, in the direction of lattice rotation, there is double slip for the pyramidal and basal slip systems. Therefore, on this great circle, approximately 
(a)

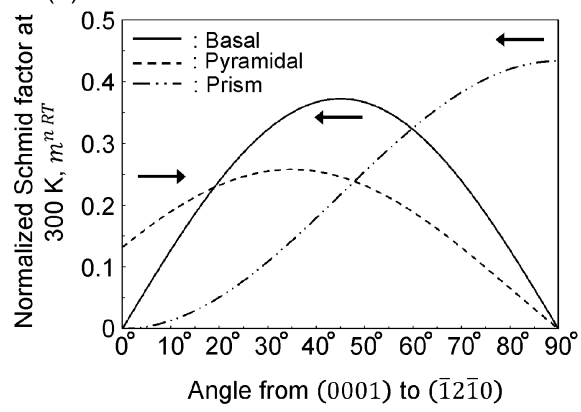

(b)

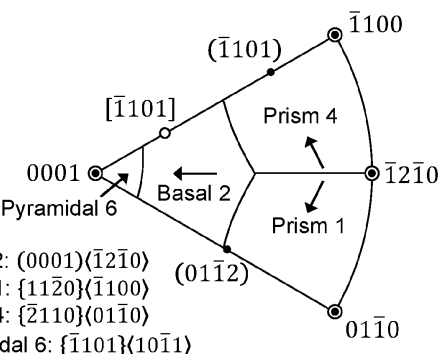

Fig. 12. Lattice rotation direction considering the normalized Schmid factor at $300 \mathrm{~K}$. (a) Relationship between the normalized Schmid factor and angle from (0001) to (1210). (b) Active slip system in a standard unit stereographic triangle for $\alpha-\mathrm{Al}_{2} \mathrm{O}_{3}$. The arrows indicate the direction in which the lattice rotates.

$19^{\circ}$ from the (0001) plane is the stable orientation for plastic deformation in uniaxial compression. Figure 12(b) shows an active slip system in a standard unit stereographic triangle for $\alpha-\mathrm{Al}_{2} \mathrm{O}_{3}$. The arrows indicate the direction in which the lattice rotates. From these results, the stable orientation for plastic deformation is obtained at the boundary where the pyramidal slip and the basal slip are active. The position of the main component is about $22^{\circ}$ from (0001) on the great circle from (0001) to (1100), and about $20^{\circ}$ from (0001) on the great circle from (0001) to $(01 \overline{1} 0)$. In the inverse pole figure obtained by the measurement, as shown in Fig. 6, the position of the main component is located approximately $15^{\circ}$ from (0001). Therefore, a shift of 4 to $7^{\circ}$ is observed in the calculated results. However, since a substantially similar texture was formed, it is believed that the obtained texture was formed by slip deformation due to the activity of the slip system in $\alpha-\mathrm{Al}_{2} \mathrm{O}_{3}$ at room temperature $(300 \mathrm{~K})$.

As shown in Fig. 7, for the coating formed with a nozzle angle of $90^{\circ}$, the volume fraction of the main component increased as the gas flow rate increased. However, when the gas flow rate exceeded $20 \mathrm{~L} / \mathrm{min}$, almost no further increase in the volume fraction of the main component can be seen. It is considered that the development of the texture with increasing gas flow rate is due to the increase in the velocity of the particles. The energy of the particles at the time of collision with the substrate increases because of the high velocity, and the particles undergo large plastic deformation. In general, it is known that when a texture is formed by plastic deformation accompanying the activation of a slip system, the texture develops with increasing strain. ${ }^{32)}$ Similar characteristics have also been obtained for $\mathrm{AD}$ coating using Ni particles. ${ }^{24)}$ On the other hand, the texture does not develop further when the gas flow rate reaches a certain level. It is reported that He gas usually gives a higher impact velocity at the same gas flow rate than air. ${ }^{6)}$ Thus, authors have considered that the texture will develop at the time of deposition by He gas when the $\mathrm{N}_{2}$ gas behave nearly same as air. However, the texture was not developed. At present, it is not known whether the impact velocity of He gas was actually low than usual due to the problems of $\mathrm{AD}$ device, or whether there was some factor that prevent the development of texture. Therefore, authors would like to consider the reason by actual measuring of the particle velocity in the future.

\subsection{Effect of substrate heating on texture}

It is considered that heating the substrate during coating formation by the $\mathrm{AD}$ method provides thermal energy in addition to kinetic energy due to particle collision at the time of deposition. Hence, deposition of the coating seems to become easier. It has a possibility for changing the formation texture of the coating by the addition of the thermal energy. However, the effect of substrate heating on the formation of a preferential orientation of the coating has not been clarified.

In this study, a fiber texture was formed by heating the substrate during deposition so that the (0001) plane was almost parallel to the coating plane. This is a different texture from that formed at $300 \mathrm{~K}$. Previously, the authors reported that (0001) fiber texture was formed by the heat treatment of the specimen for $5 \mathrm{~h}$ at 1173,1273 and 1573 after deposition of $\mathrm{Al}_{2} \mathrm{O}_{3}$ coating by $\mathrm{AD}$ at room temperature. ${ }^{14)}$ The surface energy for the (0001) plane calculated by an ab initio method is the lowest for $\mathrm{Al}_{2} \mathrm{O}_{3} .{ }^{54}$ ) The grains exist at the surface of the as-deposited coating and/ or the grains reaching the surface of the coating during grain growth under heat treatment in which the (0001) plane is parallel to the coating plane increase preferentially in order to reduce the energy of the coating. Thus, the (0001) fiber texture has developed. The microstructure of the coating deposited by heating the substrate shown in this research was different from that of the coating formed by heat treatment after deposition. ${ }^{14)}$ Hence, the mechanism of (0001) fiber texture formation in this research is different from the mechanism indicated in Ref. 14. Microstructural observations revealed no large difference in the microstructure of the $\alpha-\mathrm{Al}_{2} \mathrm{O}_{3}$ coating deposited from 300 to $573 \mathrm{~K}$. Since the CRSS for the slip systems in $\alpha-\mathrm{Al}_{2} \mathrm{O}_{3}$ bulk material changes with temperature, ${ }^{48)-50)}$ it is considered that the temperature changes the texture of the coating.

As shown in 4.1, we assume that the twin system is inactive, and only the basal, prism, and pyramidal slip systems are activated. Thus, in this stereographic triangle, seven slip systems, (0001)[ $\overline{1} 2 \overline{1} 0],(\overline{1} 2 \overline{1} 0)[\overline{1} 010]$, (12 $\overline{1} 0)[10 \overline{1} 0],(\overline{2} 110)[01 \overline{1} 0],(11 \overline{2} 0)[\overline{1} 100],(\overline{1} 101)[10 \overline{1} 1]$, and $(10 \overline{1} 1)[1101]$, are the main slip systems. Since the CRSS for each slip system does not decrease at the same 
(a)

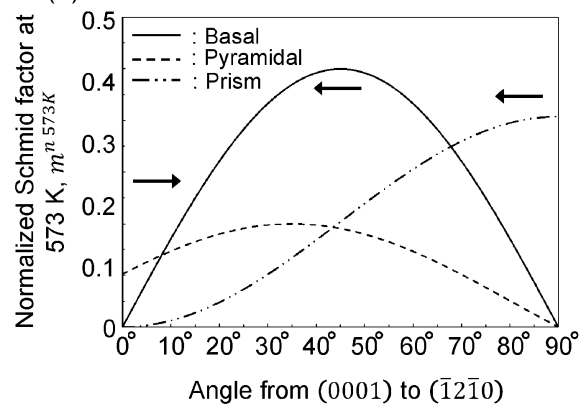

(b)

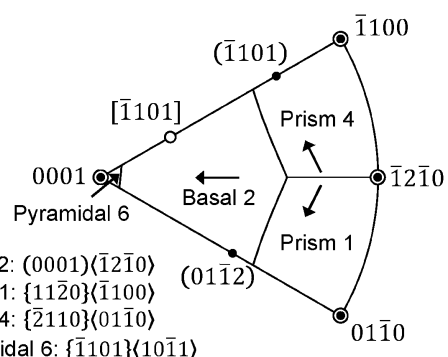

Fig. 13. Lattice rotation direction considering the normalized Schmid factor at $573 \mathrm{~K}$. (a) Relationship between the normalized Schmid factor and angle from (0001) to ( $\overline{1} 2 \overline{1} 0)$. (b) Active slip system in a standard unit stereographic triangle for $\alpha-\mathrm{Al}_{2} \mathrm{O}_{3}$. The arrows indicate the direction in which the lattice rotates.

rate, the ease of slipping activity in each slip system differs from that at $300 \mathrm{~K}^{48)-50)}$ Here, we assume that the substrate is heated to $573 \mathrm{~K}$ and that the particles are deformed by collision with the substrate in a state where the temperature of the particles is increased to $573 \mathrm{~K}$. The value of CRSS at $573 \mathrm{~K}$ for the basal, prism, and pyramidal slip systems is $1.6,1.7$, and $4.0 \mathrm{GPa}$, respectively. At room temperature, the CRSS for the prism slip system is the lowest. However, at $573 \mathrm{~K}$, the CRSS for the basal slip system is lower than that for the prism and pyramidal slip systems. As in 4.1, taking into account the slip system activity due to the difference in the CRSS, the normalized Schmid factor in the basal, prism, and pyramidal slip system at $573 \mathrm{~K}, m_{\text {bas }}^{\mathrm{n} 573 \mathrm{~K}}, m_{\mathrm{pri}}^{\mathrm{n} 573 \mathrm{~K}}$, and $m_{\mathrm{pyr}}^{\mathrm{n} 573 \mathrm{~K}}$, respectively, can be expressed as

$$
\begin{aligned}
m_{\mathrm{bas}}^{\mathrm{n} 573 \mathrm{~K}} & =\frac{m_{\mathrm{bas}}}{\left(\frac{\tau_{\mathrm{bas}}^{573 \mathrm{~K}}}{\tau_{\mathrm{pri}}^{573 \mathrm{~K}}}\right)} \\
m_{\mathrm{pri}}^{\mathrm{n} 573 \mathrm{~K}} & =\frac{m_{\mathrm{pri}}}{\left(\frac{\tau_{\mathrm{pri}}^{573 \mathrm{~K}}}{\tau_{\mathrm{pri}}^{573 \mathrm{~K}}}\right)} \\
m_{\mathrm{pyr}}^{\mathrm{n} 573 \mathrm{~K}} & =\frac{m_{\mathrm{pyr}}}{\left(\frac{\tau_{\mathrm{pyr}}^{573 \mathrm{~K}}}{\tau_{\mathrm{pri}}^{573 \mathrm{~K}}}\right)}
\end{aligned}
$$

where $\tau_{\text {bas }}^{573 \mathrm{~K}}, \tau_{\text {pri }}^{573 \mathrm{~K}}$, and $\tau_{\mathrm{pyr}}^{573 \mathrm{~K}}$ are the CRSS for the basal, prism and pyramidal slip systems at $573 \mathrm{~K}$, respectively.

After determining the normalized Schmid factor for each slip system for compression axis at $573 \mathrm{~K}$, the nor- malized Schmid factor with the highest value for each compression axis is plotted in Fig. 13. Figure 13(a) shows the normalized Schmid factor on the great circle from (0001) to (12 10$)$. The direction of lattice rotation in each slip system on the great circle is indicated by arrows. In this case, the highest values of the normalized Schmid factor in the pyramidal slip system range from 0 to $8^{\circ}$. For the basal and prims slip systems, the highest values range from 8 to $68^{\circ}$ and from 68 to $90^{\circ}$, respectively. Furthermore, from the direction of lattice rotation, there is double slip for the pyramidal and basal slip system. Therefore, on this great circle, approximately $8^{\circ}$ from the (0001) plane is the stable orientation for plastic deformation for uniaxial compression. Figure 13(b) shows an active slip system in a standard unit stereographic triangle for $\alpha-\mathrm{Al}_{2} \mathrm{O}_{3}$. The arrows indicate the direction in which the lattice rotates. From these results, the stable orientation for plastic deformation is obtained at the boundary where the pyramidal and basal slip systems are active. The position of the main component is about $10^{\circ}$ from the (0001) plane on the great circle from (0001) to ( $\overline{1} 100)$, and about $9^{\circ}$ from the $(0001)$ plane on the great circle from $(0001)$ to $(01 \overline{1} 0)$. In the inverse pole figure obtained by the measurement as shown in Fig. 9, the position of the main component corresponds to the (0001) plane. Therefore, a shift of 8 to $10^{\circ}$ is observed in the calculated results. However, a substantially similar texture was formed, which can be explained as being because the obtained texture was formed by slip deformation due to the activity of the slip system in $\alpha$ $\mathrm{Al}_{2} \mathrm{O}_{3}$ at high temperature. In order to explain the shift of the main component of the texture for calculation and experiment, further research is needed.

\section{Conclusions}

The development of texture in an $\alpha-\mathrm{Al}_{2} \mathrm{O}_{3}$ coating formed by the $\mathrm{AD}$ method for different deposition conditions was examined. When the temperature of the substrate was $300 \mathrm{~K}$ (room temperature), the main component of the texture was oriented approximately $15^{\circ}$ from the (0001) plane. Almost the same texture was formed whether the nozzle angle was 90 or $60^{\circ}$. It was found that the main component of the texture is located at almost the same position as the stable orientation of plastic deformation. The stable orientation can be explained by considering the active slip system and the CRSS. This indicates that plastic deformation of particles contributes to coating formation in the $\mathrm{AD}$ method. When the substrate was heated, the main component was oriented in the $(0001)$ plane. The change of texture can be explained by the change in the CRSS for each slip system as a function of temperature.

Acknowledgement This research was supported by the "Advanced Low Carbon Technology Research and Development Program" from the Japan Science and Technology Agency. Furthermore, this research was supported by a grantin-aid for scientific research (C) (15K06501) and (B) (18H01745) from the Japan Society for the Promotion of Science. The authors greatly appreciate the grants. 


\section{References}

1) H. Shelton, C. D. Hendricks, Jr. and R. F. Wuerker, J. Appl. Phys., 31, 1243-1246 (1960).

2) H. Tsuwa, Y. Aketa and T. Ide, J. Jpn. Soc. Precis. Eng., 38, 659-666 (1972).

3) T. Ide, Y. Mori, I. Konda, N. Ikawa and H. Yagi, J. Jpn. Soc. Precis. Eng., 57, 887-892 (1991).

4) C. Hayashi, Oyo Buturi, 54, 687-693 (1985).

5) J. Akedo, J. Am. Ceram. Soc., 89, 1834-1839 (2006).

6) J. Akedo, J. Therm. Spray Technol., 17, 181-198 (2008).

7) E. Fuchita, E. Tokizaki and Y. Sakka, J. Ceram. Soc. Jpn., 118, 767-770 (2010).

8) E. Fuchita, E. Tokizaki, E. Ozawa and Y. Sakka, J. Ceram. Soc. Jpn., 118, 948-951 (2010).

9) E. Fuchita, E. Tokizaki, E. Ozawa and Y. Sakka, J. Ceram. Soc. Jpn., 119, 271-276 (2011).

10) E. Fuchita, E. Tokizaki and E. Ozawa, J. Jpn. Soc. Powder Powder Metall., 63, 937-946 (2016).

11) D.-W. Lee, H.-J. Kim, Y.-H. Kim, Y.-H. Yun and S.-M. Nam, J. Am. Ceram. Soc., 94, 3131-3138 (2011).

12) K. Naoe, M. Nishiki and A. Yumoto, J. Therm. Spray Technol., 22, 1267-1274 (2013).

13) K. Naoe, K. Sato and M. Nishiki, J. Ceram. Soc. Jpn., 122, 110-116 (2014).

14) M. Hasegawa, K. Akiyama, Y. Oki, M. Tanaka, S. Kitaoka and Y. Kagawa, Mater. Trans., 57, 1714-1719 (2016).

15) M. Tanaka, S. Kitaoka, M. Yoshida, O. Sakurada, M. Hasegawa, K. Nishioka and Y. Kagawa, J. Eur. Ceram. Soc., 37, 4155-4161 (2017).

16) H. Park, J. Kim, S. B. Lee and C. Lee, J. Therm. Spray Technol., 26, 327-339 (2017).

17) K. Naoe, H. Temmei, M. Nishiki and J. Kusukawa, J. Jpn. Therm. Spray Soc., 52, 68-73 (2015).

18) M. Lebedev, J. Akedo and T. Ito, J. Cryst. Growth, 275, e1301-e1306 (2005).

19) T. Shibuya, T. Mizuno, A. Iuchi and M. Hasegawa, Mater. Trans., 61, 540-547 (2020).

20) M. Hasegawa, T. Shibuya, A. Iuchi and T. Mizuno, J. Jpn. Therm. Spray Soc., 57, 88-96 (2020).

21) J. Akedo and M. Lebedev, Jpn. J. Appl. Phys., 38, 5397-5401 (1999).

22) R. Inada, K. Shibukawa, C. Madada, Y. Nakanishi and Y. Sakurai, J. Power Sources, 253, 181-186 (2014).

23) F. Cao, H. Park, J. Heo, J. Kwon and C. Lee, J. Therm. Spray Technol., 22, 1109-1119 (2013).

24) M. Hasegawa, K. Kimura, K. Aoki and M. Komuro, Mater. Trans., 60, 2305-2310 (2019).

25) J. Akedo and M. Kiyohara, J. Smart Process., 3, 158166 (2014).

26) K. N. Lee, R. A. Miller and N. S. Jacobson, J. Am. Ceram. Soc., 78, 705-710 (1995).

27) C. V. Cojocaru, D. Lévesque, C. Moreau and R. S. Lima, Surf. Coat. Tech., 216, 215-223 (2013).

28) B. T. Richards, M. R. Begley and H. N. G. Wadley, J. Am. Ceram. Soc., 98, 4066-4075 (2015).

29) B. T. Richards, S. Sehr, F. Franqueville, M. R. Begley and H. N. G. Wadley, Acta. Mater., 103, 448-460 (2016).

30) M. Tanaka, T. Matsudaira, M. Wada, S. Kitaoka, M. Yoshida, O. Sakurada and Y. Kagawa, J. Soc. Mater. Sci. Jpn., 64, 431-437 (2015).

31) C. S. Barrett and L. H. Levenson, Trans. AIME, 137, 112-127 (1940).

32) U. F. Kocks, C. N. Tome and H.-R. Wenk, "Texture and Anisotropy", Cambridge University Press, Cambridge (1998) pp. 179-281.

33) M. Hasegawa, M. Yamamoto and H. Fukutomi, Acta. Mater., 51, 3939-3950 (2003).

34) M. Hasegawa and H. Fukutomi, Mat. Sci. Eng. AStruct., 508, 106-113 (2009).

35) M. Hasegawa, M. Iwashita, Y. Kubota, P. Dymáček and F. Dobeš, Mat. Sci. Eng. A-Struct., 756, 237-247 (2019).

36) H. Fukutomi, Y. Konno, K. Okayasu, M. Hasegawa and H. Nakatsugawa, Mat. Sci. Eng. A-Struct., 527, 61-64 (2009).

37) Y. Ma and K. J. Bowman, J. Am. Ceram. Soc., 74, 2941-2944 (1991).

38) A. H. Heuer, N. J. Tighe and R. M. Cannon, J. Am. Ceram. Soc., 63, 53-58 (1980).

39) W. H. Rhodes, D. J. Sellers and T. Vasilos, J. Am. Ceram. Soc., 58, 31-34 (1975).

40) K. Pawlik, J. Pospiech and K. Lüche, Text. Microstruct., 1418, 25-30 (1991).

41) U. F. Kocks, C. N. Tome and H.-R. Wenk, "Texture and Anisotropy", Cambridge University Press, Cambridge (1998) p. 149.

42) P. Sarobol, M. Chandross, J. D. Carroll, W. M. Mook, D. C. Bufford, B. L. Boyce, K. Hattar, P. Kotula and A. C. Hall, J. Therm. Spray Technol., 25, 82-93 (2016).

43) J. Lankford, W. W. Predebon, J. M. Staehler, G. Subhash, B. J. Pletka and C. E. Anderson, Mech. Mater., 29, 205-218 (1998).

44) B. J. Hockey, J. Am. Ceram. Soc., 54, 223-231 (1971).

45) H. M. Chan and B. R. Lawn, J. Am. Ceram. Soc., 71, 29-35 (1988).

46) Y. Wang and D. E. Mikkola, J. Am. Ceram. Soc., 75, 3252-3256 (1992).

47) N. K. Bourne, J. C. F. Millett, M. Chen, J. W. McCauley and D. P. Dandekar, J. Appl. Phys., 102, 073514 (2007).

48) J. D. Clayton, Int. J. Plast., 26, 1357-1386 (2010).

49) J. D. Clayton, Proc. R. Soc. London, Ser. A, 465, 307334 (2009).

50) K. P. D. Lagerlöf, A. H. Heuer, J. Castaing, J. P. Riviére and T. E. Mitchell, J. Am. Ceram. Soc., 77, 385-397 (1994).

51) E. K. Beauchamp, M. J. Carr and R. A. Graham, J. Am. Ceram. Soc., 68, 696-699 (1985).

52) J. D. Snow and A. H. Heuer, J. Am. Ceram. Soc., 56, 153-157 (1973).

53) W. F. Hosford, "Mechanical Behavior of Materials", Cambridge University Press, Cambridge (2010) p. 123.

54) A. Marmier and S. C. Parker, Phys. Rev. B, 69, 115409 (2004) 